NASA CONTRACTOR REPORT

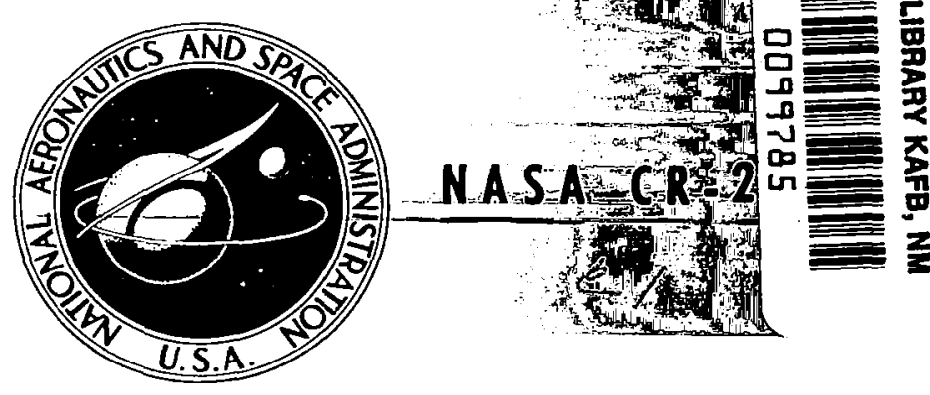

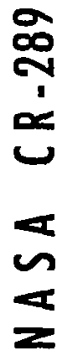

TABLES OF ELLIPTIC INTEGRALS

by William Joel Nellis

Prepared under Grant No. NsG-293 by

IOWA STATE UNIVERSITY

Ames, Iowa

for

NATIONAL AERONAUTICS AND SPACE ADMINISTRATION • WASHINGTON, D. C. • AUGUST 1965 


\section{TABLES OF ELLIPTIC INTEGRALS}

By William Joel Nellis

Distribution of this report is provided in the interest of information exchange. Responsibility for the contents resides in the author or organization that prepared it.

Prepared under Grant No. NsG-293 by

IOWA STATE UNIVERSITY

$$
\text { Ames, Iowa }
$$

for

\section{NATIONAL AERONAUTICS AND SPACE ADMINISTRATION}



TABLE OF CONTENTS

I. INTRODUCTION I

II. DEFINITION AND PROPERTIES OF THE R FUNCTION 2

III. DESCRIPTION OF TABLE 1 8

IV. DESCRIPTION OF TABLES 2 AND $3 \quad 10$

V. DESCRIPTION OF TABLE 4

VI. EXAMPLES 14

VII. TABLES 22

VIII. LITERATURE CITED 41

IX. ACKNOWLEDGEMENTS 42

X. APPENDIX: FORTRAN SUBROUTINE PROGRAM FOR COMPUTING $R_{F} \quad 43$ AND $R_{G}$ BY MEANS OF DESCENDING GAUSS OR ASCENDING IANDEN TRANSFORMATIONS 


\section{LIST OF TABLES}

Table

Page

1 Integrals with algebraic or trigonometric integrands

2 Reduction formulas for complete integrals of the first

25 and second kinds

3 Reduction formulas for incomplete integrals of the

29 first and second kinds

$4 a$ Numerical table of $R_{F}(x, y, 1)$

4b Numerical table of $R_{G}(x, y, 1)$ 


\section{INTRODUCTION}

The tables present a method of evaluating elliptic integrals of the first and second kinds by means of the $R$ function, a hypergeometric function of several variables (1). The genera 1 method is to reduce an integral of elliptic type to an $R$ function by means of the integral formulas of Table 1. The formulas of Table 2 (for complete integrals) or Table 3 (for incomplete integrals) are then used to reduce the $\mathrm{R}$ function to a linear combination of two standard $R$ functions and an algebraic function. The two standard functions, $\mathrm{R}_{\mathrm{K}}$ and $\mathrm{R}_{\mathrm{E}}$ (in the complete case) or $\mathrm{R}_{\mathrm{F}}$ and $\mathrm{R}_{\mathrm{G}}$ (in the incomplete case), are norma 1 elliptic integrals of the first and second kinds (2). Table 4 gives numerical values of the norma 1 integra $1 s$ over a limited range; it is intended only to give an idea of the behavior of the functions and should not be used for interpolation near $\mathrm{x}=0$ or $\mathrm{y}=0$.

Table 1 can also be used to express elliptic integrals of the third kind (as well as many other integrals) in terms of the $R$ function, but tables for reduction and numerical evaluation of integrals of the third kind are not included. Unti 1 such tables are developed, the reader is referred to conventional tables of elliptic integrals, for example (3, 4, 5), which deal with integrals of all three kinds. For integrals of the first two kinds, it is believed that the present scheme of reduction offers significant advantages in conciseness. 


\section{DEFINITION AND PROPERTIES OF THE R FUNCTION}

A few basic properties (1) of the $R$ function are essential for the use of these tables. We shall give first the definition of $R$ as an infinite series and the most important integral representation. Let a function $R$ of $n$ complex variables $z_{1}, \ldots \ldots z_{n}$ and $n+1$ complex parameters $a, b_{1}, \ldots \ldots b_{n}$ be defined by the following power series if $\left|1-z_{i}\right|<1(i=1, \ldots, n)$ and by its analytic continuation if $\left|\operatorname{argz}{ }_{i}\right|<\pi$ :

$$
\begin{aligned}
& R\left(a ; b_{1} \cdots, b_{n} ; z_{1}, \ldots, z_{n}\right) \\
& =\sum_{m_{1}=0}^{\infty} \cdots \sum_{m_{n}=0}^{\infty} \frac{\left(a, m_{1}+\cdots+m_{n}\right)\left(b_{1}, m_{1}\right) \cdots \cdot\left(b_{n}, m_{n}\right)}{\left(b_{1}+\cdots+b_{n}, m_{1}+\ldots \cdot+m_{n}\right) m_{1} ! \cdots \cdot \cdot m_{n} !}\left(1-z_{1}\right)^{m_{1}} \ldots\left(1-z_{n}\right)^{m_{n}},
\end{aligned}
$$

where $(a, m)=a(a+1) \ldots(a+m-1)=\Gamma(a+m) / \Gamma(a)$ and $\Gamma$ is the gamma func t1on. Let

$$
c=b_{1}+\ldots+b_{n}
$$

and define $a^{\prime}$ by

$$
c=a+a^{\prime} \text {. }
$$

We assume that $c$ is not zero or a negative integer. Provided that a and $a^{\prime}$ have positive real parts, the $R$ function can be represented by a single integra 1:

$$
B\left(a, a^{\prime}\right) R\left(a ; b_{1}, \ldots, b_{n} ; z_{1}, \ldots, z_{n}\right)=\int_{0}^{\infty} t^{a^{\prime}-1} \prod_{i=1}^{n}\left(t+z_{i}\right)^{-b} d t,
$$


where $B\left(a, a^{\prime}\right)=\Gamma(a) \Gamma\left(a^{\prime}\right) / \Gamma(c)$ is the beta function.

The $\mathrm{R}$ function has two important properties, symmetry and homogeneity. Symmetry is apparent from either representation: $R\left(a ; b_{1}, \ldots ., b_{n}\right.$; $z_{1}, \ldots ., z_{n}$ ) is invariant under permutation of the subscripts $1, \ldots ., n$, that is, $R$ does not change when the $b$ 's and $z$ 's are perinuted together.

A scale factor common to all the z's can be removed by changing the variable of integration in 2.2. Thus, $R$ is homogeneous of degree $-a$ in the variables $z_{1}, \ldots ., z_{n}$ : $R\left(a ; b_{1}, \ldots ., b_{n} ; s z_{1}, \ldots ., s z_{n}\right)=s^{-a} R\left(a ; b_{1}, \ldots ., b_{n} ; z_{1}, \ldots ., z_{n}\right)$.

This property is often used to make all the arguments of an $R$ function less than or equal to unity.

The substitution $t=\tau^{-1}$ in 2.2 leads to the Euler transformation, which allows us to change the value of the a-parameter:

$R\left(a ; b_{1}, \ldots ., b_{n} ; z_{1}, \ldots ., z_{n}\right)=\left(\prod_{i=1}^{n} z_{i}^{-b}{ }^{-}\right) R\left(a^{\prime} ; b_{1}, \ldots, b_{n} ; z_{1}^{-1}, \ldots . ., z_{n}^{-1}\right)$

For the case $n=2$, there is another relation which can be used to change the value of the a-parameter:

$$
\mathrm{g}_{2}{ }^{\mathrm{a}} \mathrm{R}\left(\mathrm{a} ; \mathrm{b}_{1}, \mathrm{~b}_{2} ; \mathrm{z}_{1}, \mathrm{z}_{2}\right)=\mathrm{z}_{2}{ }^{\mathrm{b}} \mathrm{l}_{\mathrm{R}\left(\mathrm{b}_{1} ; \mathrm{a}, \mathrm{a}^{\prime} ; \mathrm{z}_{1}, \mathrm{z}_{2}\right)}
$$

Equation 2.5 has no ana logue for $n>2$. Equations $2.3,2.4$, and 2.5 are actually valid without restriction on $a$ or $a^{\prime}$. 
There are a few special cases of the parameters and variables which provide very useful relations. If one of the $b$-parameters in 2.1 is zero, say $b_{n}$, then

$$
\left(b_{n}, m_{i}\right)=\left(0, m_{i}\right)=\delta_{m_{i} 0}
$$

is a Kronecker delta, and

$R\left(a ; b_{1}, \ldots . ., b_{n-1}, 0 ; z_{1}, \ldots . \cdot, z_{n}\right)=R\left(a ; b_{1}, \ldots . ., b_{n-1} ; z_{1}, \ldots .,, z_{n-1}\right)$

If any two arguments are equa 1 , say $z_{1}=z_{2}$, then 2.2 shows that

$$
\begin{aligned}
R\left(a ; b_{1}, . ., b_{n} ; z_{2}, z_{2}, z_{3}, . . ., z_{n}\right) & \\
& =R\left(a ; b_{1}+b_{2}, b_{3}, . ., b_{n} ; z_{2}, . . ., z_{n}\right) .
\end{aligned}
$$

If any one of the arguments vanishes, say $z_{1}, 2.2$ again shows that

$$
\begin{aligned}
B\left(a, a^{\prime}\right) R\left(a ; b_{1}, . . ., b_{n} ; 0, z_{2}, . . \cdot, z_{n}\right) \\
=B\left(a, a^{\prime}-b_{1}\right) R\left(a ; b_{2}, \ldots ., b_{n} ; z_{2}, . . ., z_{n}\right),
\end{aligned}
$$

provided that $\operatorname{Re}\left(a^{\prime}-b_{1}\right)>0$.

Tables 2 and 3 were derived from recursion formulas for the $R$ function. Let

$$
\begin{aligned}
R & =R\left(a ; b_{1}, \ldots, b_{n} ; z_{1}, \ldots ., z_{n}\right), \\
R(a \pm 1) & =R\left(a \pm 1 ; b_{1}, . ., b_{n} ; z_{1}, . ., z_{n}\right) \\
R\left(b_{i} \pm 1\right) & =R\left(a ; b_{1}, \ldots ., b_{i} \pm 1, \ldots ., b_{n} ; z_{1}, \ldots ., z_{n}\right) .
\end{aligned}
$$


For any $n$ the basic recursion formulas are

$$
\begin{aligned}
(c-1) R\left(b_{i}-1\right) & =\left(a^{\prime}-1\right) R+a z_{i} R(a+1),(i=1, \ldots, n), \\
c R & =\sum_{i=1}^{n} b_{i} R\left(b_{i}+1\right), \\
c R(a-1) & =\sum_{i=1}^{n} b_{i} z_{i} R\left(b_{i}+1\right), \\
\operatorname{acR}(a+1) & =\sum_{i=1}^{n} b_{i} z_{i}^{-1}\left[c R-a^{\prime} R\left(b_{i}+1\right)\right] .
\end{aligned}
$$

For $\mathfrak{n}=2$, these relations imply three further formulas that are particularly useful in practice:

$$
\begin{aligned}
b_{i}\left(z_{j}-z_{i}\right) R\left(b_{1}+1\right) & =c\left[z_{j} R-R(a-1)\right] \\
b_{1} b_{2}\left(z_{1}-z_{2}\right)^{2} R\left(b_{1}+1, b_{2}+1\right) & =c(c+1)\left[-z_{1} z_{2} R+\left(z_{1}+z_{2}\right) R(a-1)-R(a-2)\right] \\
a z_{1} z_{2} R(a+1) & =a^{\prime} R(a-1)-\sum_{i=1}^{2}\left(b_{i}-a\right) z_{1} R_{1}
\end{aligned}
$$

For $\mathrm{n}=3,2.9-2.12$ imply two formulas that are likewise quite usefu 1 in practice:

$$
\begin{gathered}
a^{\prime} b_{i}\left(z_{i}^{\left.-z_{j}\right)\left(z_{1}-z_{k}\right) R\left(b_{i}+1\right)}=\operatorname{cR}\left[z_{1} z_{2} z_{3} \sum_{m=1}^{3} b_{m} z^{-1}-a^{\prime} z_{i}\left(z_{j}+z_{k}\right)\right]\right. \\
+a^{\prime} z_{i} c R(a-1)-a c z_{1} z_{2} z_{3} R(a+1)
\end{gathered}
$$




$$
\begin{aligned}
a(a+1) z_{1} z_{2} z_{3} R(a+2) & =a z_{1} z_{2} z_{3} \sum_{i=1}^{3}\left(1-a^{\prime}+b_{i}\right) z_{i}{ }^{-1} R(a+1) \\
& +\left(a^{\prime}-1\right) \sum_{i=1}^{3}\left(a-b_{1}\right) z_{1} R(a)+a^{\prime}\left(a^{\prime}-1\right) R(a-1)
\end{aligned}
$$

An $R$ function of four variables $\left(0<x<y, z\right.$, w) with $a=a^{\prime}=1$ can be reduced to a linear combination of two $R$ functions of three variables :

$$
\begin{aligned}
(1-\alpha)(y-x)^{\beta}(z-x)^{\gamma}(w-x)^{2-\alpha-\beta-\gamma_{R}(1 ; \alpha, \beta, \gamma, 2-\alpha-\beta-\gamma ; x, y, z, w)} \\
\quad=R\left(1-\alpha ; \beta, \gamma, 2-\alpha-\beta-\gamma ;(y-x)^{-1},(z-x)^{-1},(w-x)^{-1}\right) \\
\quad-x^{1-\alpha_{R}\left(1-\alpha ; \beta, \gamma, 2-\alpha-\beta-\gamma ; y(y-x)^{-1}, z(z-x)^{-1}, w(w-x)^{-1}\right) .}
\end{aligned}
$$

By applying an Euler transformation, we obtain the alternative form

$$
\begin{gathered}
(1-\alpha) R(1 ; \alpha, \beta, \gamma, 2-\alpha-\beta-\gamma ; x, y, z, w)=R(1 ; \beta, \gamma, 2-\alpha-\beta-\gamma ; y-x, z-x, w-x) \\
-x^{1-\alpha} y^{-\beta} z^{-\gamma_{w} \alpha+\beta+\gamma-2} R\left(1 ; \beta, \gamma, 2-\alpha-\beta-\gamma ; y^{-1}(y-x), z^{-1}(z-x), w^{-1}(w-x)\right) .
\end{gathered}
$$

An $R$ function with two $b$-parameters and having complex conjugate arguments can be reduced (if elliptic) to a linear combination of $\mathrm{R}_{\mathrm{K}}$ and $R_{E}$. The transformations of the complete normal integrals are then

$$
\begin{aligned}
& R_{K}(z, \bar{z})=R_{K}(|z|, u), \\
& R_{E}(z, \bar{z})=2 R_{E}(|z|, u)-|z| R_{K}(|z|, u),
\end{aligned}
$$


where $2 u=|z|+\operatorname{Re} z$ and $\bar{z}$ is the complex conjugate of $z$.

If an $R$ function has three $b$-parameters, one real argument, and two complex conjugate arguments, it can be reduced (if elliptic) to a linear combination of $R_{F}, R_{G}$, and an algebraic function. The transformations of the incomplete normal integrals are then

$$
\begin{aligned}
R_{F}(x, z, \bar{z}) & =R_{F}(u, v, w), \\
2 R_{G}(x, z, \bar{z}) & =4 R_{G}(u, v, w)-|z| R_{F}(u, v, w)-\sqrt{x},
\end{aligned}
$$

where $x$ is rea 1 and

$$
\begin{aligned}
& 2 u=|z|+\operatorname{Re} z, \\
& 2 v=|z|+x+\left(|z|^{2}-2 x \operatorname{Re} z+x^{2}\right)^{1 / 2}, \\
& 2 w=|z|+x-\left(|z|^{2}-2 x \operatorname{Re} z+x^{2}\right)^{1 / 2} .
\end{aligned}
$$




\section{DESCRIPTION OF TABLE 1}

The first section of Table 1 contains integrals such as

$$
\int_{\lambda}^{\mu}(t-x)^{\alpha}(t-y)^{\beta}(t-z)^{\gamma}(t-w)^{\delta} d t,
$$

where one of the limits, $\lambda$ or $\mu$, is a singularity of the integrand, that is, either $\lambda$ or $\mu$ is equa 1 to $x, y, z, w$ or $\pm \infty$. If $x$ is complex, $t-x$ is to be given its principal value: $|\arg (t-x)|<\pi$. Integrals of the form

$$
\int_{\lambda}^{\mu} t^{\alpha}\left(t^{2}-x\right)^{\beta}\left(t^{2}-y\right)^{\gamma}\left(t^{2}-z\right)^{\delta} d t
$$

can be reduced to the above form (with $w=0$ ) by substituting $t^{2}=\tau$, and similarly for factors of type $\left(t^{3}-x\right)$, etc.

In 6.3 and 6.4 the upper limit is assumed greater than the lower limit. In 6.3 the upper limit is a singularity of the integrand, and in 6.4 , the lower limit. If the integral to be evaluated contains a factor $(z-t)^{\beta}$ instead of $(t-z)^{\beta}$, that is, if $z$ lies to the right instead of to the left of the range of integration, one need only replace $(t-z)^{\beta}$ by $(z-t)^{\beta}$ on the left side of 6.3 or 6.4 and $(y-z)^{\beta}$ by $(z-y)^{\beta}$ In the coefficient on the right side (since $t$ takes the value $y$ at one point of the interval of integration). The arguments of the $R$ function are unchanged; both $x-z$ and $y-z$ wi 11 now be negative, but their ratio is positive as before.

The second section of Table I contains some integrals with trigonometric integrands. Statements analogous to those about algebraic 
integrals can also be made about trigonometric ones. For example, in 6.7 if $(1-p \cos \phi)$ is negative, replace $(1-p \cos \theta)^{\delta}$ by $(p \cos \theta-1)^{\delta}$ on the left hand side and $(1-p)^{\delta}$ by $(p-1)^{\delta}$ in the coefficient of $R$ on the right hand side. The arguments of the $R$ function are unchanged; both 1-pcos $\phi$ and 1-p will now be negative, but their ratio is still positive. 


\section{DESCRIPTION OF TABLES 2 AND 3}

Table 2 (the complete case) expresses a number of $R$ functions with half-integra 1 a- and b-parameters as linear combinations of two $R$ functions, $R_{K}$ and $R_{E}$, which are taken as normal elliptic integrals of the first and second kinds, respectively:

$$
\begin{aligned}
& \mathrm{R}_{\mathrm{K}}(\mathrm{x}, \mathrm{y})=\mathrm{R}\left(\frac{1}{2} ; \frac{1}{2}, \frac{1}{2} ; \mathrm{x}, \mathrm{y}\right), \\
& \mathrm{R}_{\mathrm{E}}(\mathrm{x}, \mathrm{y})=\mathrm{R}\left(-\frac{1}{2} ; \frac{1}{2}, \frac{1}{2} ; \mathrm{x}, \mathrm{y}\right) .
\end{aligned}
$$

Table 3 (the incomplete case) expresses a number of $R$ functions with half integra 1 a- and b-parameters as linear combinations of three standard $R$ functions, one of which is algebraic:

$$
\begin{aligned}
& R_{F}(x, y, z)=R\left(\frac{1}{2} ; \frac{1}{2}, \frac{1}{2}, \frac{1}{2} ; x, y, z\right), \\
& R_{G}(x, y, z)=R\left(-\frac{1}{2} ; \frac{1}{2}, \frac{1}{2}, \frac{1}{2} ; x, y, z\right), \\
& (x y z)^{-1 / 2}=R\left(\frac{3}{2} ; \frac{1}{2}, \frac{1}{2}, \frac{1}{2} ; x, y, z\right) .
\end{aligned}
$$

Each complete integra 1 is a multiple of an incomplete integra 1 with one vanishing argument, as shown by 2.8 :

$$
\begin{aligned}
& 2 R_{F}(x, y, 0)=\pi R_{K}(x, y), \\
& 4 R_{G}(x, y, 0)=\pi R_{E}(x, y) .
\end{aligned}
$$

We are concerned primarily with $R$ functions in which all the parameters $a, b_{1}, \ldots ., b_{n}$ are half-integral or integral. If the $a$ - 
parameter is a negative integer, the series 2.1 terminates and the $R$ function is a polynomial. If $a^{\prime}$ is a negative integer, the Euler transformation 2.4 shows that $R$ is then algebraic. A number of such cases are included in Table 3 ( the coefficients multiplying the normal elliptic integrals being zero), but they cannot arise from single integrals of the type in Table 1 , since the integral representation 2.2 converges only if $a$ and $a^{\prime}$ have positive real parts.

Excluding such algebraic cases, we have the following rules of thumb:

(1) If $\mathrm{n}=2$ and al1 parameters but the c-parameter are halfintegral, we have a complete elliptic integral of the first or second kind; e.g., $R\left(\frac{3}{2} ; \frac{3}{2}, \frac{1}{2} ; x, y\right)$.

(2) If there are three b-parameters, all half-integral, and if one of the pair $\left(a, a^{\prime}\right)$ is a half integer (the other being an integer), we have an incomplete elliptic integral of the first or second kind; e.g., $R\left(\frac{1}{2} ; \frac{3}{2}, \frac{1}{2}, \frac{1}{2} ; x, y, z\right)$.

(3) If there are three b-parameters, two half-integral and one integral, and if the a-parameter is half-integral, we have a complete elliptic integral of the third kind; e.g., $R\left(\frac{1}{2} ; \frac{1}{2}, \frac{1}{2}, 1 ; x, y, z\right)$.

(4) If there are four b-parameters, three half-integral and one integra1, we have an incomplete elliptic integral of the third kind; e.g., $R\left(\frac{1}{2} ; \frac{1}{2}, \frac{1}{2}, \frac{1}{2}, 1 ; w, x, y, z\right)$.

(5) If we have four $b$-parameters, $a l l$ half-integral, and if $a=$ $a^{\prime}=1$, we have an incomplete integral of the first or second kind; e.g., $R\left(1 ; \frac{1}{2}, \frac{1}{2}, \frac{1}{2}, \frac{1}{2} ; w, x, y, z\right)$. 
There are many $R$ functions which fall into one of these classes only after being subjected to some (perhaps quadratic or cubic) transformation. For example, $R\left(\frac{1}{4} ; \frac{3}{4}, \frac{1}{4} ; x, y\right)$ is a complete elliptic integra 1 of the first kind.

Table 2 gives some reduction formulas for class (1) in which the cparameter is positive and the largest $b$-parameter is $3 / 2$. Table 3 gives some reduction formulas for class (2). Equation 2.18 reduces $R$ functions of class (5) to two $R$ functions of class (1) or (2). If an $R$ function is not found in Table 2 or 3 but falls irito class (1) or (2), one can extend these tables by use of 2.9-2.17, especially by 2.13-2.15 in the complete case and by 2.16 and 2.17 in the incomplete case. 


\section{DESCRIPTION OF TABLE 4}

Table 4 gives numerical values of $R_{F}$ and $R_{G}$. Homogeneity can always be used to make the arguments of $R$ less than or equal to unity. Thus, the table contains values of $R_{F}(x, y, 1)$ and $R_{G}(x, y, 1)$ only in the domain $0 \leq x, y \leq 1$. The table was calculated with the IBM 7074 computer of the Iowa State University Computation Center. Two distinct methods were employed. One program was based on the power series expansion of $R$ given by 2.1. The other program utilized descending Gauss or ascending Landen transformations. The algorithms for the latter method are described in detail in (6). The power series expansion converges very slowly for values of the arguments close to zero. The program based on it yielded results only in the region $.20 \leq x, y \leq 1$. The other program computed the normal integrals throughout the whole domain. Both programs yielded identical results in the region where both computed the functions.

The table is intended to give an idea of the behavior of $R_{F}$ and $R_{G}$; it should not be used for interpolation. If numerical values not contained in the table are desired, the algorithms in (6) or, if a computer is available, the Fortran subroutine in the Appendix may be employed.

Complete integrals are contained in the table as the case in which one of the arguments is zero. For example, by 4.1

$$
R_{K}(3 / 4,1)=(2 / \pi) R_{F}(0,3 / 4,1)
$$

The table is redundant in that both $R_{F}$ and $R_{G}$ are symmetric in $x$ and $y$, that is, $R_{F}(x, y, 1)=R_{F}(y, x, 1)$, and similarly for $R_{G}$. Note also that $R_{G}$ increases and $R_{F}$ decreases as either $x$ or $y$ increases. 


\section{EXAMPLES}

1. Reduce the following integral to an $R$ function:

$$
I=\int_{-2}^{4}(t+2)^{-1 / 2}(t+4)^{-3 / 2}(6-t)^{1 / 2}(t+8)^{-1 / 2} d t
$$

Rewrite the integral to obtain

$$
\left.I-\int_{-2}^{4}[t-(-2)]^{-1 / 2}[t-(-4)]^{-3 / 2}(6-t)\right)^{1 / 2}[t-(-8)]^{-1 / 2} d t
$$

The lower limit is a singularity and is less than the upper limit. In 6.4 , on the left side let

$$
(t-v)^{\delta} \rightarrow(v-t)^{\delta}=(6-t)^{1 / 2}
$$

and on the right side let

$$
(y-v)^{\delta} \rightarrow(v-y)^{\delta}=(6+2)^{1 / 2}
$$

Make the correspondence

$$
\begin{aligned}
& x=: \quad z=-8 \quad v=6 \quad \alpha--\frac{1}{2} \quad \gamma=-\frac{3}{2} \\
& y=-2 \quad w=-4 \quad a=\frac{1}{2} \quad \beta=-\frac{1}{2} \quad \delta=\frac{1}{2} .
\end{aligned}
$$

Therefore,

$$
I=2 \mathrm{R}\left(\frac{1}{2} ; \frac{1}{2}, \frac{3}{2},-\frac{1}{2}, 0 ; 2,4, \frac{1}{4}, 1\right) .
$$

By 2.6 , 


$$
I=2 \mathrm{R}\left(\frac{1}{2} ; \frac{1}{2}, \frac{3}{2},-\frac{1}{2} ; 2,4, \frac{1}{4}\right) \text {. }
$$

2. Reduce the following integral to an $R$ function:

$$
I=\int_{g}^{h}(t+d)^{1 / 2}(t-f)^{1 / 2}(h-t)^{-1 / 2} d t, \quad-d<f<g<h .
$$

Equation 6.3 is appropriate. We have the choice of setting either $\beta, \gamma$, or $\delta$ equal to zero. Make the correspondence

$$
\begin{array}{llll}
\mathrm{y}=\mathrm{h} & \mathrm{w}=-\mathrm{d} & \alpha=-\frac{1}{2} & \gamma=\frac{1}{2} \\
\mathrm{x}=\mathrm{g} & \mathbf{v}=\mathbf{f} & \beta=0 & \delta=\frac{1}{2} .
\end{array}
$$

Therefore,

$I=2(h-g)^{1 / 2}(h+d)^{1 / 2}(h-f)^{1 / 2} R\left(\frac{1}{2} ; 0, \frac{1}{2}, \frac{1}{2}, \frac{5}{2} ; \frac{z-g}{z-h}, \frac{d+g}{d+h}, \frac{g-f}{h-f}, 1\right)$.

Using symmetry and 2.6 we obtain

$I=2(h-g)^{1 / 2}(h+d)^{1 / 2}(h-f)^{1 / 2} R\left(\frac{1}{2} ; \frac{5}{2},-\frac{1}{2},-\frac{1}{2} ; 1, \frac{d+g}{d+h}, \frac{g-f}{h-f}\right)$.

3. Express Legendre's incomplete elliptic integral of the first kind as an $R$ function.

$$
I=\int_{0}^{x}\left(1-t^{2}\right)^{-1 / 2}\left(1-k^{2} t^{2}\right)^{-1 / 2} d t, 0<k, x<1 .
$$

Substitute $t^{2}=\tau$ to obtain

$$
2 I=\int_{0}^{x^{2}} \tau-1 / 2(1-\tau)^{-1 / 2}\left(1-k^{2} \tau\right)^{-1 / 2} d \tau,
$$


and

$$
2 k I=\int_{0}^{x^{2}} t^{-1 / 2}(1-t)^{-1 / 2}\left(1 / k^{2}-t\right)^{-1 / 2} d t
$$

In 6.4 choose $\beta=0$. On the left hand side of 6.4 let

$$
\begin{aligned}
& (t-w)^{\gamma} \rightarrow(w-t)^{\gamma}=(1-t)^{-1 / 2}, \\
& (t-v)^{\delta} \rightarrow(v-t)^{\delta}=\left(1 / k^{2}-t\right)^{-1 / 2} .
\end{aligned}
$$

On the right hand side let

$$
\begin{aligned}
& (y-w)^{\gamma} \rightarrow(w-y)^{r}=1, \\
& (y-v)^{\delta} \rightarrow(v-y)^{\delta}=k .
\end{aligned}
$$

Make the correspondence

$$
\begin{array}{llll}
y=0 & w=1 & \alpha=-\frac{1}{2} & \gamma=-\frac{1}{2} \\
x \rightarrow x^{2} & v=\frac{1}{k^{2}} & \beta=0 & \delta=-\frac{1}{2} .
\end{array}
$$

The integra 1 becomes

$$
\begin{aligned}
& I=x R\left(\frac{1}{2} ; \frac{1}{2}, \frac{1}{2}, \frac{1}{2} ; 1-x^{2}, 1-k^{2} x^{2}, 1\right), \\
& I=x R_{F}\left(1-x^{2}, 1-k^{2} x^{2}, 1\right) .
\end{aligned}
$$

When $x$ is equal to unity the integral is Legendre's complete integral of the first kind, and is given by 


$$
I=R_{F}\left(0,1-k^{2}, 1\right), \quad x=1
$$

4. Reduce the following integral to a standard $R$ function:

$$
I=\int_{0}^{1} t^{-1 / 2}\left(t^{2}+1\right)^{-1 / 2} d t
$$

The substitution $t^{2}=\tau$ yields

$$
I=2 R\left(\frac{1}{4} ; \frac{3}{4}, \frac{1}{2} ; 1,2\right)
$$

We can obtain an $R$ function whose $a$ - and $b$-parameters are al1 halfintegral by reducing the integral to an $R$ with one real argument and two complex conjugate arguments, and then using the transformation 2.22 .

Rewrite the integral as

$$
I=\int_{0}^{1} t^{-1 / 2}(t+i)^{-1 / 2}(t-i)^{-1 / 2} d t
$$

In 6.4 make the correspondence

$$
\begin{array}{llll}
x=1 & w=-i & \alpha=-\frac{1}{2} & \gamma=-\frac{1}{2} \\
y=0 & v=i & \beta=0 & \delta=-\frac{1}{2} .
\end{array}
$$

The integral becomes

$$
I=2 R_{F}(1+i, 1-i, 1)
$$

By 2.22, 


$$
I=2 R_{F}(u, v, w)
$$

where

$$
\begin{aligned}
& 2 u=\sqrt{2}+1 \\
& 2 v=\sqrt{2}+2 \\
& 2 w=\sqrt{2} .
\end{aligned}
$$

5. Reduce the following integral to an $R$ function whose a-parameter is ha 1f-integra 1 :

$$
I=\int_{0}^{\infty} t^{1 / 2}(t+f)^{-3 / 2}(t+g)^{-1 / 2}(t+h)^{-1 / 2} d t, f, g, h>0 .
$$

In 2.2 make the correspondence

$$
\begin{array}{lll}
b_{1}=\frac{3}{2} & b_{3}=\frac{1}{2} & a^{\prime}=\frac{3}{2} \\
b_{2}=\frac{1}{2} & c=\frac{5}{2} & a=1 .
\end{array}
$$

The integral becomes

$$
3 I=2 R\left(1 ; \frac{3}{2}, \frac{1}{2}, \frac{1}{2} ; f, g, h\right) \text {. }
$$

Using the Euler transformation 2.4, we obtain the result,

$$
3 f(f g h)^{1 / 2} I=2 R\left(\frac{3}{2} ; \frac{3}{2}, \frac{1}{2}, \frac{1}{2} ; f^{-1}, g^{-1}, h^{-1}\right) .
$$

6. Express the following $R$ function as another $R$ whose arguments lie between zero and unity, and then evaluate numerically: 


$$
\mathrm{R}=\mathrm{R}\left(\frac{1}{2} ; \frac{1}{2}, \frac{1}{2}, \frac{1}{2} ; 1,2,4\right) \text {. }
$$

Use homogeneity 2.3 to obtain

$$
2 R=R_{F}(0.25,0.50,1.00)
$$

Table 4 yields

$$
\mathrm{R}=0.3764 \text {. }
$$

7. Evaluate numerically the following definite integral:

$$
I=\int_{2}^{3}(t+1)^{-3 / 2}(t-1)^{1 / 2}(3-t)^{-1 / 2} d t
$$

Using $6.3,2.6$, and symmetry, the integra 1 becomes

$$
I=2^{-3 / 2} R\left(\frac{1}{2} ; \frac{3}{2}, \frac{1}{2},-\frac{1}{2} ; \frac{3}{4}, 1, \frac{1}{2}\right) \text {. }
$$

By the reduction formula of Table 3 and the symetry of $R_{F}$ and $R_{G}$, we obtain

$$
I=\sqrt{2}\left[R_{F}\left(\frac{1}{2}, \frac{3}{4}, 1\right)-2 R_{G}\left(\frac{1}{2}, \frac{3}{4}, 1\right)+(2 / 3)^{1 / 2}\right] .
$$

Table 4 gives the numerical result:

$$
\begin{aligned}
& I=\sqrt{2}[1.1682-2(0.8628)+0.8165] \\
& I=0.3664 .
\end{aligned}
$$

8. Express the following integral as an $R$ function: 


$$
I=\int_{\phi}^{\pi / 2}\left(k^{2} \sin ^{2} \theta-1\right)^{-1 / 2} d \theta, k \sin \phi>1 .
$$

In 6.6 make the correspondence

$$
\begin{array}{llll}
\alpha=0 & \gamma=0 & \mathrm{P}=-1 & \mathrm{r}=\mathrm{k}^{2} \\
\beta=0 & \delta=-\frac{1}{2} & \mathrm{q}=0 .
\end{array}
$$

The integral becomes

$$
I=\left(k^{2}-1\right)^{-1 / 2} \cos \phi R_{F}\left(\sin ^{2} \phi, \frac{k^{2} \sin ^{2} \phi-1}{k^{2}-1}, 1\right) .
$$

9. Express $R\left(\frac{1}{2} ; \frac{5}{2}, \frac{1}{2} ; x, y\right)$ as a linear combination of $R_{K}$ and $R_{E}$. The purpose of this example is to illustrate how the reduction formula tables may be extended.

Use 2.13 to increase by one a b-parameter of $R\left(\frac{1}{2} ; \frac{3}{2}, \frac{1}{2} ; x, y\right)$. For this $R$ function,

$$
a=\frac{1}{2}, a^{\prime}=\frac{3}{2}, c=2 \text {. }
$$

By 2.13,

$$
3(y-x) R\left(\frac{1}{2} ; \frac{5}{2}, \frac{1}{2} ; x, y\right)=4\left[y R\left(\frac{1}{2} ; \frac{3}{2}, \frac{1}{2} ; x, y\right)-R\left(-\frac{1}{2} ; \frac{3}{2}, \frac{1}{2} ; x, y\right] .\right.
$$

Using the reduction formulas of Table 2 for the two $R$ functions on the right, we obtain

$$
\begin{array}{r}
9(y-x)^{2} R\left(\frac{1}{2} ; \frac{5}{2}, \frac{1}{2} ; x, y\right)=12 y\left[2 y R_{K}(x, y)-2 R_{E}(x, y]\right. \\
-4\left[2 x y R_{K}(x, y)-2(2 x-y) R_{E}(x, y)\right] .
\end{array}
$$


Simplifying, we obtain the desired result,

$$
9(y-x){ }^{2} R\left(\frac{1}{2} ; \frac{5}{2}, \frac{1}{2} ; x, y\right)=8 y(3 y-x) R_{K}(x, y)+16(x-2 y) R_{E}(x, y) .
$$

The identical result may be obtained by setting $z=0$ in the reduction formula for $R\left(\frac{1}{2} ; \frac{5}{2}, \frac{1}{2}, \frac{1}{2} ; x, y, z\right)$ given in Table 3 , and using 2.8 . 


\section{TABLES}

Table 1. Integrals with algebraic or trigonometric integrands

In 6.1 and 6.2 ,

$$
a=-(\alpha+\beta+\gamma+\delta+1), \operatorname{Re} a>0 \text {. }
$$

$(6.1)$

$$
\begin{aligned}
& \int_{-\infty}^{x}(z-t)^{\alpha}(w-t)^{\beta}(v-t)^{\gamma}(s-t)^{\delta} d t \\
= & a^{-1} R(a ;-\alpha,-\beta,-\gamma,-\delta ; z-x, w-x, v-x, s-x), \\
(x \leq z, w, v, s),(\text { substitute } t=x-u) . & \int^{\infty}(t-z)^{\alpha}(t-w)^{\beta}(t-v)^{\gamma(t-s)^{\delta}} d t \\
= & a^{-1} R(a ;-\alpha,-\beta,-\gamma,-\delta ; x-z, x-w, x-v, x-s), \\
& (z, w, v, s \leq x),(s u b s t i t u t e t=x+u) .
\end{aligned}
$$

Equations 6.3 and 6.4 remain valid if both sides are multiplied by $(-1)^{\beta}$, that is, if $(t-z)^{\beta}$ is replaced by $(z-t)^{\beta}$ and $(y-z)^{\beta}$ by $(z-y)^{\beta}$. The same is true for $(-1)^{\gamma},(-1)^{\delta}$, or any combination of the three, such as $(-1)^{\beta+\gamma}$ (see Section III). In 6.3 and 6.4 ,

$$
a=a+1, \operatorname{Re} a>-1
$$


Table 1. (Continued)

$(6.3)$

$\int_{x}^{y}(y-t)^{\alpha}(t-z)^{\beta}(t-w)^{\gamma}(t-v)^{\delta} d t$

$=a^{-1}(y-x)^{\alpha+1}(y-z)^{\beta}(y-w)^{\gamma}(y-v)^{\delta}$

$-R\left(a ;-\beta,-\gamma,-\delta, \alpha+\beta+\gamma+\delta+2 ; \frac{x-z}{y-z}, \frac{x-w}{y-w}, \frac{x-v}{y-v}, 1\right)$,

(substitute $t=(u y+x)(u+1)^{-1}$ ).

$(6.4)$

$$
\begin{aligned}
& \int_{y}^{x}(t-y)^{\alpha}(t-z)^{\beta}(t-w)^{\gamma}(t-v)^{\delta} d t \\
& =a^{-1}(x-y)^{\alpha+1}(y-z)^{\beta}(y-w)^{\gamma}(y-v)^{\delta} \\
& =R\left(a ;-\beta,-\gamma,-\delta, \alpha+\beta+\gamma+\delta+2 ; \frac{x-z}{y-z}, \frac{x-w}{y-w}, \frac{x-v}{y-v}, 1\right),
\end{aligned}
$$

(substitute $t=(u y+x)(u+1)^{-1}$ ).

(6.5) $\int_{0}^{\phi}(\sin \theta)^{\alpha}\left(\sin ^{2} \phi-\sin ^{2} \theta\right)^{\beta}(\cos \theta)^{\gamma}\left(p+q \cos ^{2} \theta+r \sin ^{2} \theta\right)^{\delta} d \theta$

$$
=\frac{1}{2}(p+q)^{\delta}(\sin \phi)^{\alpha+2 \beta+1} B\left(\frac{\alpha+1}{2}, \beta+1\right)
$$

- R $\left(\frac{\alpha+1}{2} ; \frac{1-\gamma}{2},-\delta, \frac{\alpha+2 \beta+\gamma+2 \delta+2}{2} ; \cos ^{2} \phi, \frac{p+q \cos ^{2} \phi+r \sin ^{2} \phi}{p+q}, 1\right)$,

$\left(0 \leq \phi \leq \frac{\pi}{2} ; \operatorname{Re} \alpha, \operatorname{Re} \beta>-1\right)$, (substitute $\left.\sin \theta=(1+t)^{-1 / 2} \sin \phi\right)$. 
Table 1. (Continued)

$(6.6)$

$$
\begin{aligned}
& \int_{\phi}^{\pi / 2}(\cos \theta)^{\alpha}\left(\cos ^{2} \phi-\cos ^{2} \theta\right)^{\beta}(\sin \theta)^{\gamma}\left(p+q \cos ^{2} \theta+r \sin ^{2} \theta\right)^{\delta} d \theta \\
& \quad=\frac{1}{2}(p+r)^{\delta}(\cos \phi)^{\alpha+2 \beta+1} B\left(\frac{\alpha+1}{2}, \beta+1\right) \\
& \cdot R\left(\frac{\alpha+1}{2} ; \frac{1-\gamma}{2},-\delta, \frac{\alpha+2 \beta+r+2 \delta+2}{2} ; \sin ^{2} \phi \frac{p+q \cos ^{2} \phi+r \sin ^{2} \phi}{p+r}, 1\right), \\
& \left(0 \leq \phi \leq \frac{\pi}{2} ; \operatorname{Re} \alpha, \operatorname{Re} \beta>-1\right),\left(\operatorname{substitute} \cos \theta=(1+t)^{-1 / 2} \cos \phi\right) .
\end{aligned}
$$

$(6.7)$

$$
\begin{gathered}
\int_{0}^{\phi}(\sin \theta)^{\alpha}(\cos \theta-\cos \phi)^{\beta}(\cos \theta)^{\gamma}(1-p \cos \theta)^{\delta} \mathrm{d} \theta \\
=2^{\alpha+\beta}(1-p)^{\delta}\left(\sin \frac{\phi}{2}\right)^{\alpha+2 \beta+1} B\left(\frac{\alpha+1}{2}, \beta+1\right)
\end{gathered}
$$

$$
\begin{aligned}
& \cdot R\left(\frac{\alpha+1}{2} ;-\gamma, \frac{1-\alpha}{2},-\delta, \alpha+\beta+\gamma+\delta+1 ; \cos \phi, \frac{1+\cos \phi}{2}, \frac{1-p \cos \phi}{1-p}, 1\right), \\
& \left(0 \leq \phi \leq \frac{\pi}{2} ; \operatorname{Re} \alpha, \operatorname{Re} \beta>-1\right),\left(\text { substitute } \cos \theta=(t+\cos \phi)(t+1)^{-1}\right) . \\
& (6.8) \\
& \int_{\phi}^{\pi / 2} \overline{(\cos \theta)^{\alpha}(\sin \theta-\sin \phi)^{\beta}(\sin \theta)^{\gamma}(1-p \sin \theta)^{\delta} d \theta} \\
& =2^{\alpha+\beta}(1-p)^{\delta}\left[\sin \left(\frac{\pi}{4} \frac{\phi}{2}\right)\right]^{\alpha+2 \beta+1} B\left(\frac{\alpha+1}{2}, \beta+1\right) \\
& \cdot R\left(\frac{\alpha+1}{2} ;-\gamma, \frac{1-\alpha}{2},-\delta, \alpha+\beta+\gamma+\delta+1 ; \sin \phi, \frac{1+\sin \phi}{2}, \frac{1-p \sin \phi}{1-p}, 1\right) \text {, } \\
& \left(0 \leq \phi \leq \frac{\pi}{2} ; \operatorname{Re} \alpha, \operatorname{Re} \beta>-1\right),\left(\text { substitute } \sin \theta=(t+\sin \phi)(t+1)^{-1}\right)
\end{aligned}
$$

24 
Table 2. Reduction formulas for complete integrals of the first and second kinds

These formulas are of the form

$$
A R\left(a ; b_{1}, b_{2} ; x, y\right)=A_{K} R_{K}+A_{E} R_{E},
$$

where

$$
\begin{aligned}
& \mathrm{R}_{\mathrm{K}}=\mathrm{R}\left(\frac{1}{2} ; \frac{1}{2}, \frac{1}{2} ; \mathrm{x}, \mathrm{y}\right) \\
& \mathrm{R}_{\mathrm{E}}=\mathrm{R}\left(-\frac{1}{2} ; \frac{1}{2}, \frac{1}{2} ; \mathrm{x}, \mathrm{y}\right)
\end{aligned}
$$

\begin{tabular}{|c|c|c|c|c|c|}
\hline$a$ & $a^{\prime}$ & $\underline{b}$ & A & $A_{K}$ & ${ }_{E}$ \\
\hline$\frac{5}{2}$ & $\frac{1}{2}$ & & $3 x y(x-y)^{2}$ & $-16 x y$ & $8(x+y)$ \\
\hline$\frac{3}{2}$ & $\frac{3}{2}$ & & $(x-y)^{2}$ & $8(x+y)$ & -16 \\
\hline$\frac{1}{2}$ & $\frac{5}{2}$ & & $3(x-y)^{2}$ & $-16 x y$ & $8(x+y)$ \\
\hline$-\frac{1}{2}$ & $\frac{7}{2}$ & $\left(\frac{3}{2}, \frac{3}{2}\right)$ & $15(x-y)^{2}$ & $-8 x y(x+y)$ & $16\left(x^{2}+y^{2}-x y\right)$ \\
\hline
\end{tabular}

The symbol $\underline{b}$ is defined as

$$
\underline{b}=\left(b_{1}, b_{2}\right) \text {. }
$$


Table 2. (Continued)

\begin{tabular}{|c|c|c|c|c|c|}
\hline $\mathbf{a}$ & $a^{\prime}$ & $\underline{b}$ & A & ${ }^{A_{K}}$ & ${ }^{A} E$ \\
\hline$-\frac{3}{2}$ & $\frac{9}{2}$ & $\left(\frac{3}{2}, \frac{3}{2}\right)$ & $105(x-y)^{2}$ & $16 x y\left(-2 x^{2}-2 y^{2}+x y\right)$ & $64\left(x^{3}+y^{3}\right)-40 x y(x-y)$ \\
\hline$-\frac{5}{2}$ & $\frac{11}{2}$ & & $315(x-y)^{2}$ & $24 x^{2} y^{2}(x+y)-64 x y\left(x^{3}+y^{3}\right)$ & $\begin{array}{l}-8 x y\left(8 x^{2}+8 y^{2}+6 x y\right) \\
+128\left(x^{4}+y^{4}\right)\end{array}$ \\
\hline$\frac{5}{2}$ & $-\frac{1}{2}$ & & $3 x^{2} y(y-x)$ & $-2 x y$ & $-2 x+4 y$ \\
\hline$\frac{3}{2}$ & $\frac{1}{2}$ & & $x(y-x)$ & $-2 x$ & 2 \\
\hline$\frac{1}{2}$ & $\frac{3}{2}$ & & $y-x$ & $2 y$ & -2 \\
\hline$-\frac{1}{2}$ & $\frac{5}{2}$ & & $3(y-x)$ & $2 x y$ & $-4 x+2 y$ \\
\hline$-\frac{3}{2}$ & $\frac{7}{2}$ & & $15(y-x)$ & $2 x y(4 x-y)$ & $-16 x^{2}+4 y^{2}+6 x y$ \\
\hline$-\frac{5}{2}$ & $\frac{9}{2}$ & & $105(y-x)$ & $x y\left(48 x^{2}-8 y^{2}-10 x y\right)$ & $\begin{aligned} & 2 x y(16 x+9 y) \\
+ & 16\left(y^{3}-6 x^{3}\right)\end{aligned}$ \\
\hline
\end{tabular}


Table 2. (Continued)

\begin{tabular}{|c|c|c|c|c|c|}
\hline a & $a^{\prime}$ & $\underline{b}$ & A & $\mathrm{A}_{\mathrm{K}}$ & ${ }_{E}$ \\
\hline$\frac{5}{2}$ & $-\frac{3}{2}$ & & $3 x^{3} y$ & $-4 x y$ & $-x+8 y$ \\
\hline$\frac{3}{2}$ & $-\frac{1}{2}$ & & $x^{2}$ & $-x$ & 2 \\
\hline$\frac{1}{2}$ & $\frac{1}{2}$ & & $\mathrm{x}$ & 0 & 1 \\
\hline & & $\left(\frac{3}{2}, \frac{-1}{2}\right)$ & & & \\
\hline$-\frac{1}{2}$ & $\frac{3}{2}$ & & 1 & $-y$ & 2 \\
\hline$-\frac{3}{2}$ & $\frac{5}{2}$ & & 3 & $-4 x y$ & $8 x-y$ \\
\hline$-\frac{5}{2}$ & $\frac{7}{2}$ & & 15 & $x y(-24 x+y)$ & $48 x^{2}-2 y^{2}-8 x y$ \\
\hline$\frac{5}{2}$ & $-\frac{3}{2}$ & $\left(\frac{1}{2}, \frac{1}{2}\right)$ & $3 x^{2} y^{2}$ & $-x y$ & $2(x+y)$ \\
\hline$\frac{3}{2}$ & $-\frac{1}{2}$ & & $\mathrm{xy}$ & 0 & 1 \\
\hline
\end{tabular}


Table 2. (Continued)

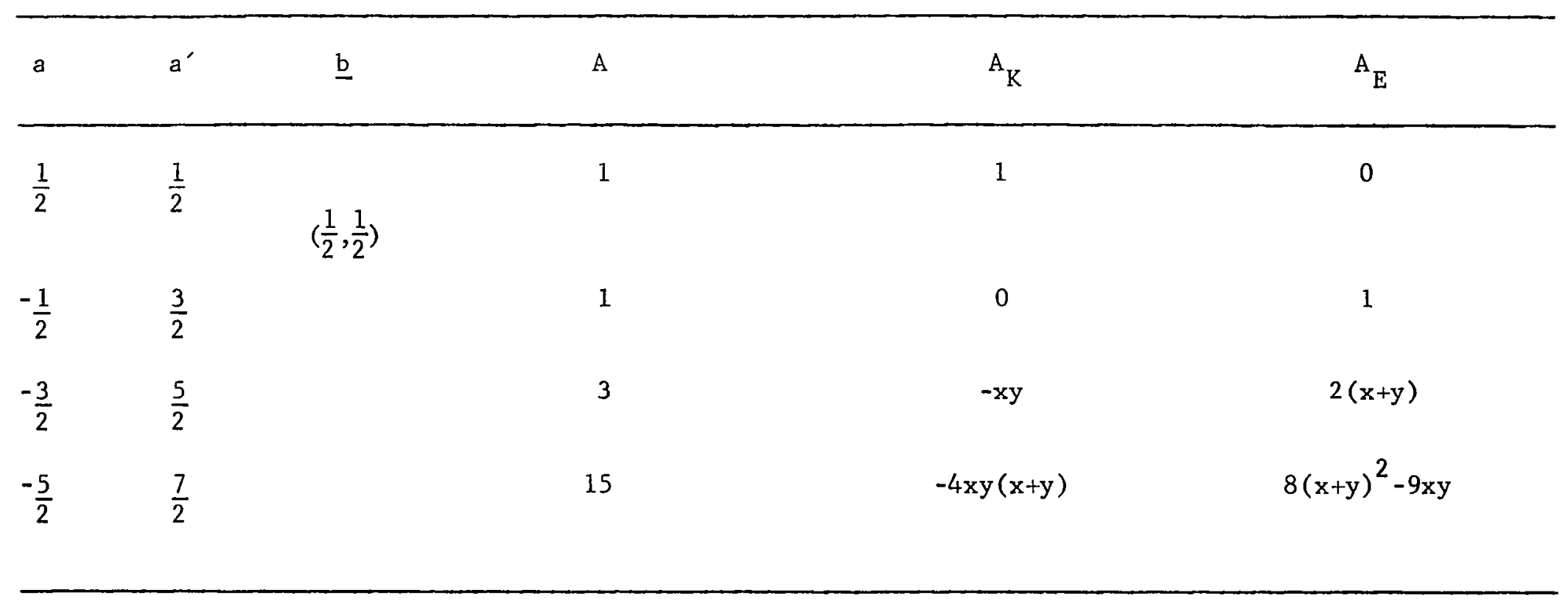


Table 3. Reduction formulas for incomplete integrals of the first and second kinds

These formulas are of the form

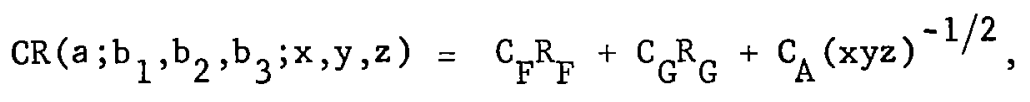

where

$$
\begin{aligned}
R_{F} & =R\left(\frac{1}{2} ; \frac{1}{2}, \frac{1}{2}, \frac{1}{2} ; x, y, z\right), \\
R_{G} & =R\left(-\frac{1}{2} ; \frac{1}{2}, \frac{1}{2}, \frac{1}{2} ; x, y, z\right), \\
(x y z)^{-1 / 2} & =R\left(\frac{3}{2} ; \frac{1}{2}, \frac{1}{2}, \frac{1}{2} ; x, y, z\right) .
\end{aligned}
$$

The symbols $s, p$, and $\underline{b}$ are defined as

$$
\begin{aligned}
& \mathrm{s}=x y+x z+y z \\
& p=x y z \\
& \underline{b}=\left(b_{1}, b_{2}, b_{3}\right)
\end{aligned}
$$


Table 3. (Continued)

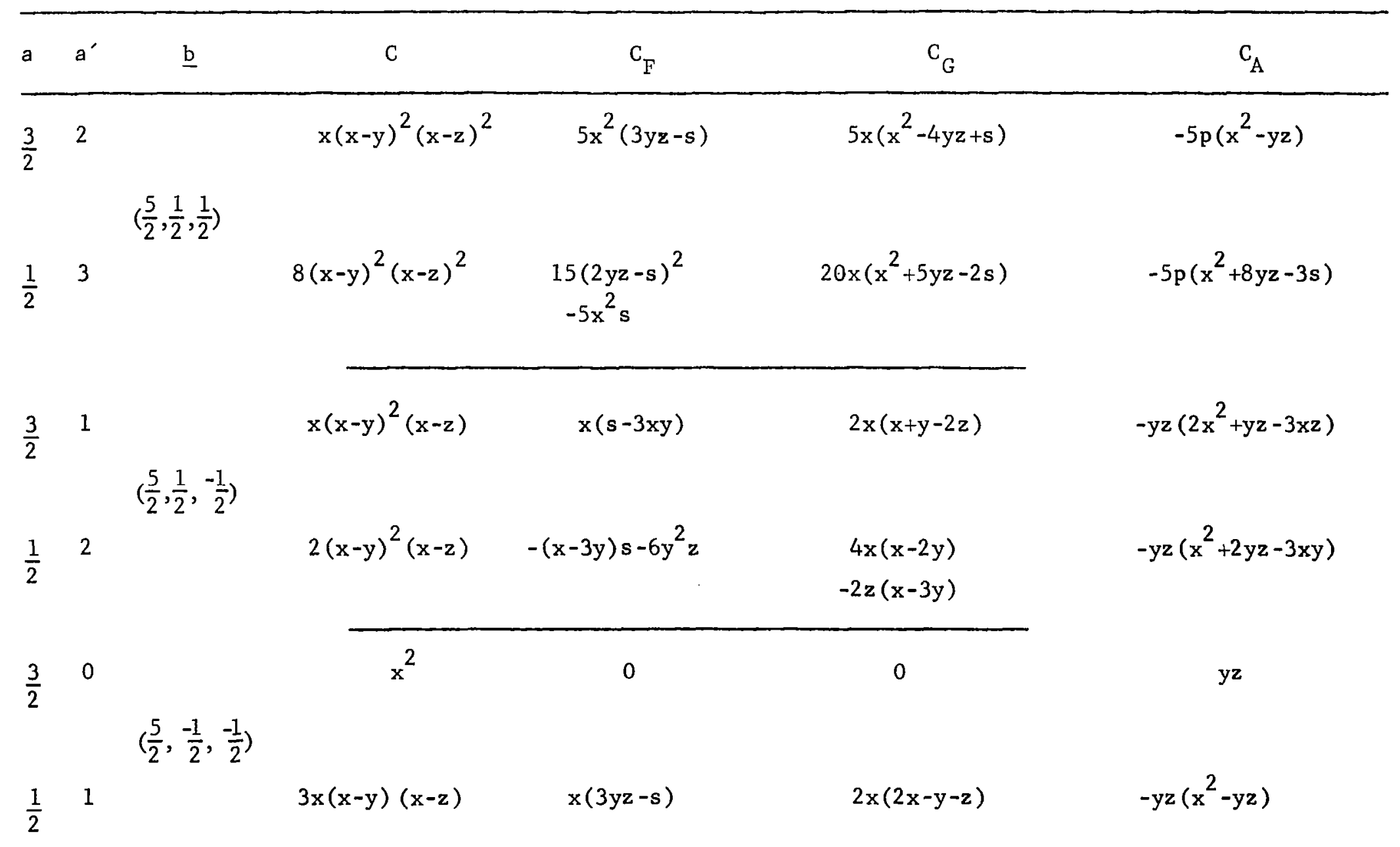


Table 3. (Continued)

\begin{tabular}{|c|c|c|c|c|c|c|}
\hline a & $a^{\prime}$ & $\underline{b}$ & $\mathrm{C}$ & $\mathrm{C}_{\mathrm{F}}$ & $\mathrm{C}_{\mathrm{G}}$ & $\mathrm{C}_{\mathrm{A}}$ \\
\hline$\frac{1}{2}$ & 3 & $\left(\frac{3}{2}, \frac{3}{2}, \frac{1}{2}\right)$ & $8(x-y)^{2}(y-z)(x-z)$ & $\begin{array}{r}15 z^{2}(x-y)^{2} \\
+15 x y(s-3 x y)\end{array}$ & $\begin{aligned} & 30 x^{2}(y-z) \\
+ & 30 y^{2}(x-z)\end{aligned}$ & $15 p(s-3 x y)$ \\
\hline$\frac{3}{2}$ & 0 & $\left(\frac{3}{2}, \frac{3}{2},-\frac{3}{2}\right)$ & xy & 0 & 0 & $z^{2}$ \\
\hline$\frac{3}{2}$ & 1 & & $(x-y)(x-z)$ & $3 x$ & -6 & $3 y z$ \\
\hline$\frac{1}{2}$ & 2 & $\left(\frac{3}{2}, \frac{1}{2}, \frac{1}{2}\right)$ & $2(x-y)(x-z)$ & $3(2 y z-5)$ & $6 x$ & $-3 p$ \\
\hline$-\frac{1}{2}$ & 3 & & $8(x-y)(x-z)$ & $3 x(2 y z-s)$ & $6(x-y)(x-z)+6 x^{2}$ & $-3 x p$ \\
\hline$-\frac{3}{2}$ & 4 & & $16(x-y)(x-z)$ & $\begin{array}{l}-s\left[(x-y)(x-z)+3 x^{2}\right] \\
+6 x p\end{array}$ & $\begin{array}{c}(x-y)(x-z)(10 x+4 y+4 z) \\
+6 x^{3}\end{array}$ & $-\left[(x-y)(x-z)+3 x^{2}\right] p$ \\
\hline$\frac{3}{2}$ & 0 & & $\mathrm{x}$ & 0 & 0 & $\mathbf{z}$ \\
\hline$\frac{1}{2}$ & 1 & $\left(\frac{3}{2}, \frac{1}{2},-\frac{1}{2}\right)$ & $x-y$ & $-y$ & 2 & $-y z$ \\
\hline
\end{tabular}


Table 3. (Continued)

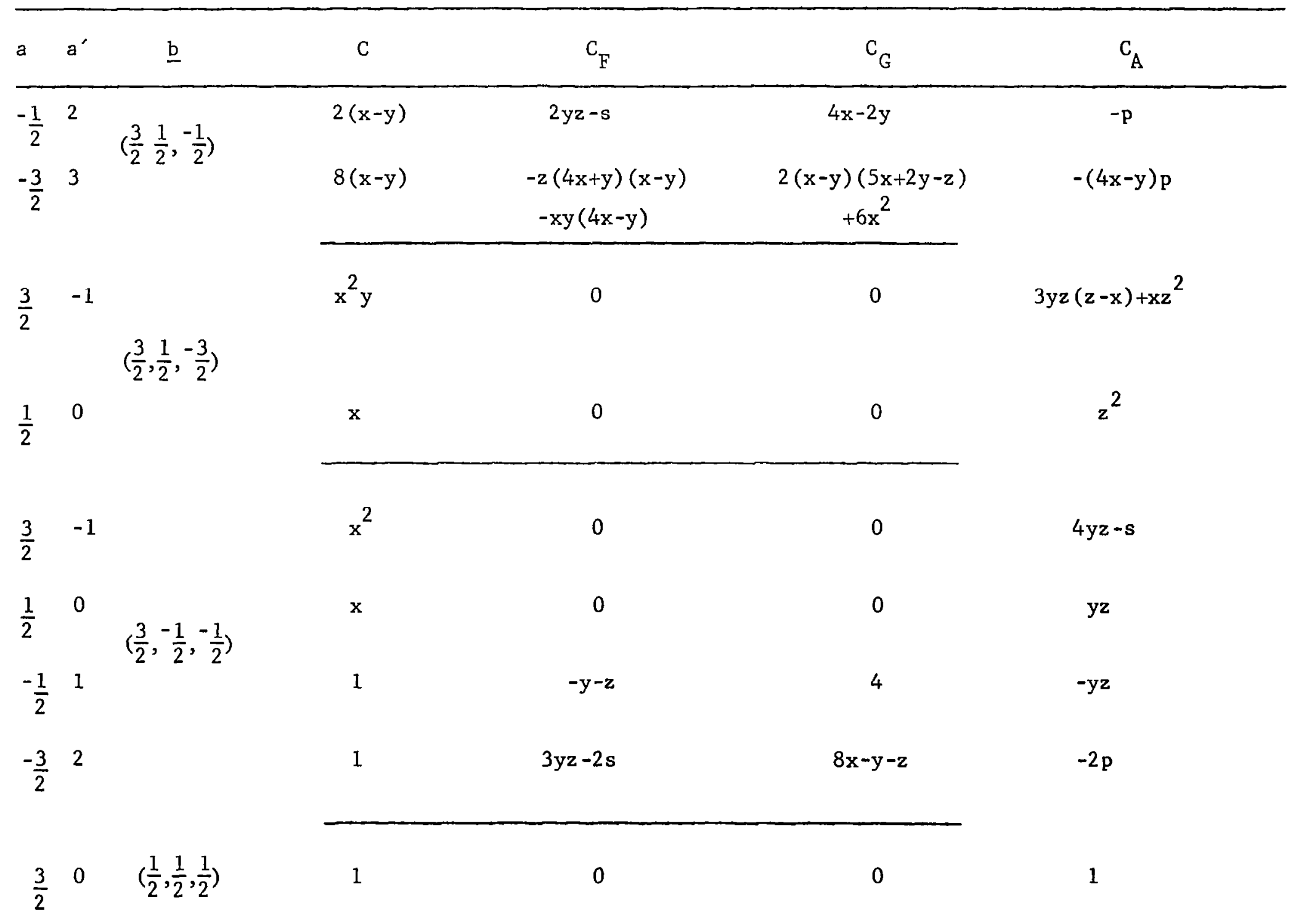


Table 3. (Continued)

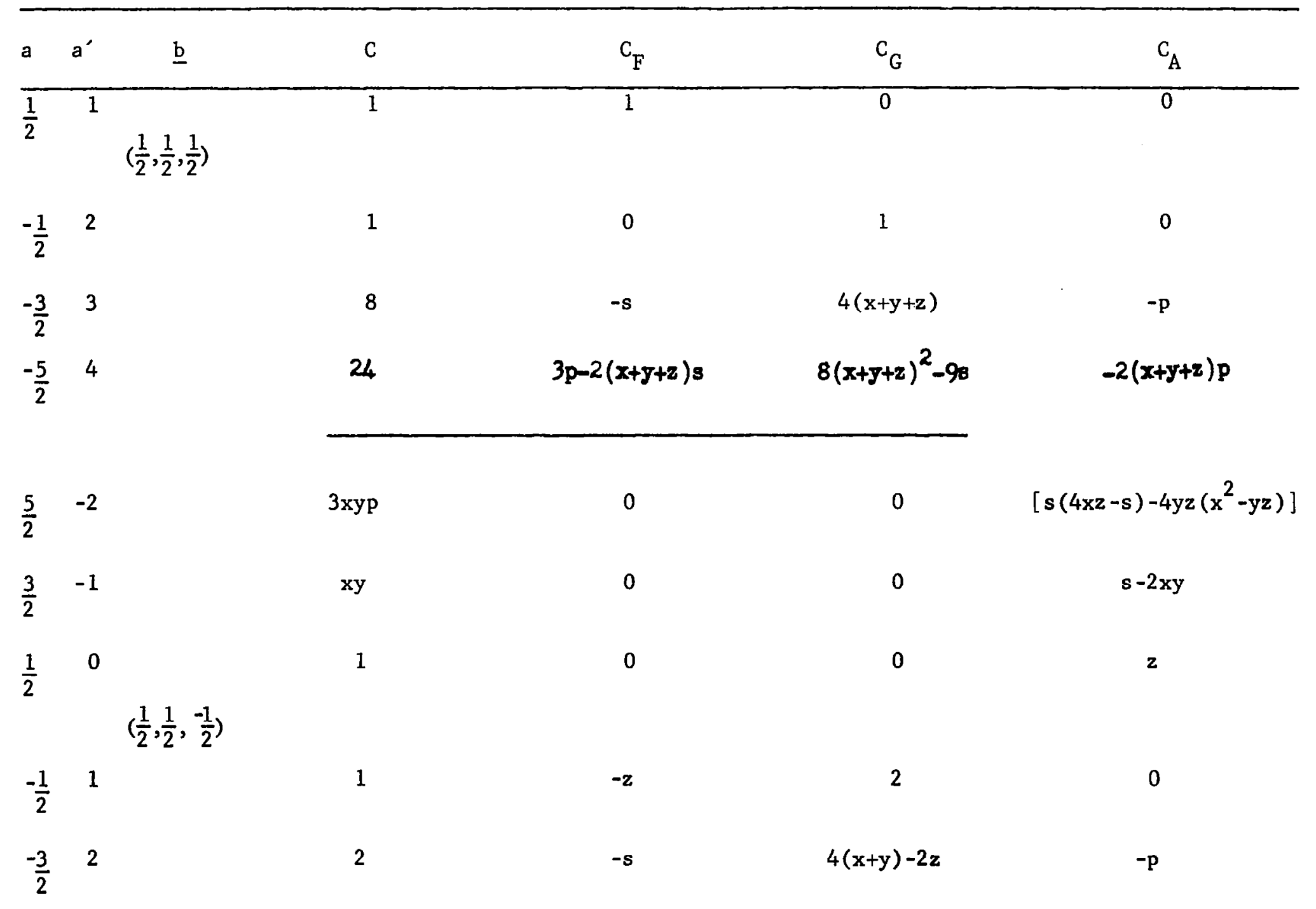


Table 3. (Continued)

\begin{tabular}{|c|c|c|c|c|c|c|}
\hline a & $a^{\prime}$ & $\underline{b}$ & C & $\mathrm{C}_{\mathrm{F}}$ & $\mathrm{c}_{\mathrm{G}}$ & $\mathrm{C}_{\mathrm{A}}$ \\
\hline$-\frac{5}{2}$ & 3 & $\left(\frac{1}{2}, \frac{1}{2},-\frac{1}{2}\right)$ & 8 & $3 p+(-3 x-3 y+2 z) s$ & $4\left(3 x^{2}+5 x y+3 y^{2}-2 z^{2}\right)-5 s$ & $(-3 x-3 y+2 z) p$ \\
\hline$\frac{3}{2}$ & -2 & & $x^{2} y^{2}$ & 0 & 0 & $4 z p-3(s-2 x y)^{2}$ \\
\hline$\frac{1}{2}$ & -1 & & $x y$ & 0 & 0 & $z(4 x y-5)$ \\
\hline 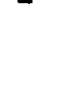 & & $\left(\frac{1}{2}, \frac{1}{2}, \frac{-3}{2}\right)$ & & & & \\
\hline$-\frac{1}{2}$ & 0 & & 1 & 0 & 0 & $z^{2}$ \\
\hline$-\frac{3}{2}$ & 1 & & 1 & $s-3 z^{2}$ & $-4 x-4 y+8 z$ & $\mathbf{p}$ \\
\hline$\frac{3}{2}$ & -2 & & $x p$ & 0 & 0 & $s^{2}-4 y z\left(x^{2}+y z\right)$ \\
\hline$\frac{1}{2}$ & -1 & & $\mathrm{x}$ & 0 & 0 & $s-2 y z$ \\
\hline & & $\left(\frac{1}{2}, \frac{-1}{2}, \frac{-1}{2}\right)$ & & & & \\
\hline$-\frac{1}{2}$ & 0 & & 1 & 0 & 0 & $y z$ \\
\hline$-\frac{3}{2}$ & 1 & & 1 & $s-3 y z$ & $-4 x+2 y+2 z$ & $\mathbf{p}$ \\
\hline
\end{tabular}


Table 4a. Numerica 1 table of $R_{F}(x, y, 1)$

$\begin{array}{llllllll}(X, Y) & 0.00 & 0.05 & 0.10 & 0.15 & 0.20 & 0.25 & 0.30\end{array}$

$\begin{array}{lllllllll}0.00 & \infty & 2.9083 & 2.5781 & 2.3890 & 2.2572 & 2.1565 & 2.0754\end{array}$

$\begin{array}{lllllllll}0.05 & 2.9083 & 2.2349 & 2.0613 & 1.9502 & 1.8679 & 1.8024 & 1.7480\end{array}$

$\begin{array}{llllllll}0.10 & 2.5781 & 2.0613 & 1.9168 & 1.8223 & 1.7513 & 1.6942 & 1.6465\end{array}$

$\begin{array}{llllllll}0.15 & 2.3890 & 1.9502 & 1.8223 & 1.7375 & 1.6733 & 1.6215 & 1.5779\end{array}$

$\begin{array}{llllllll}0.20 & 2.2572 & 1.8679 & 1.7513 & 1.6733 & 1.6140 & 1.5659 & 1.5254\end{array}$

$\begin{array}{llllllll}0.25 & 2.1565 & 1.8024 & 1.6942 & 1.6215 & 1.5659 & 1.5207 & 1.4825\end{array}$

$\begin{array}{lllllllll}0.30 & 2.0754 & 1.7480 & 1.6465 & 1.5779 & 1.5254 & 1.4825 & 1.4461\end{array}$

$\begin{array}{llllllll}0.35 & 2.0076 & 1.7015 & 1.6055 & 1.5404 & 1.4903 & 1.4493 & 1.4146\end{array}$

$\begin{array}{lllllllll}0.40 & 1.9496 & 1.6609 & 1.5695 & 1.5073 & 1.4594 & 1.4201 & 1.3867\end{array}$

$\begin{array}{lllllllll}0.45 & 1.8989 & 1.6249 & 1.5375 & 1.4778 & 1.4317 & 1.3939 & 1.3617\end{array}$

$\begin{array}{lllllllll}0.50 & 1.8541 & 1.5927 & 1.5087 & 1.4512 & 1.4067 & 1.3702 & 1.3391\end{array}$

$\begin{array}{lllllllll}0.55 & 1.8139 & 1.5634 & 1.4825 & 1.4270 & 1.3839 & 1.3485 & 1.3183\end{array}$

$\begin{array}{lllllllll}0.60 & 1.7775 & 1.5367 & 1.4585 & 1.4047 & 1.3629 & 1.3286 & 1.2993\end{array}$

$\begin{array}{lllllllll}0.65 & 1.7444 & 1.5121 & 1.4363 & 1.3841 & 1.3435 & 1.3101 & 1.2816\end{array}$

$\begin{array}{lllllllll}0.70 & 1.7139 & 1.4894 & 1.4158 & 1.3650 & 1.3255 & 1.2929 & 1.2651\end{array}$

$\begin{array}{lllllllll}0.75 & 1.6858 & 1.4682 & 1.3966 & 1.3471 & 1.3086 & 1.2768 & 1.2497\end{array}$

$\begin{array}{lllllllll}0.80 & 1.6596 & 1.4484 & 1.3787 & 1.3304 & 1.2928 & 1.2617 & 1.2352\end{array}$

$\begin{array}{lllllllll}0.85 & 1.6353 & 1.4298 & 1.3618 & 1.3147 & 1.2779 & 1.2475 & 1.2215\end{array}$

$\begin{array}{lllllllll}0.90 & 1.6124 & 1.4124 & 1.3459 & 1.2998 & 1.2638 & 1.2341 & 1.2086\end{array}$

$\begin{array}{lllllllll}0.95 & 1.5910 & 1.3959 & 1.3309 & 1.2858 & 1.2505 & 1.2213 & 1.1963\end{array}$

$\begin{array}{llllllll}1.00 & 1.5708 & 1.3802 & 1.3166 & 1.2724 & 1.2378 & 1.2092 & 1.1847\end{array}$ 
Table 4a. (Continued)

$\begin{array}{llllllll}(X, Y) & 0.35 & 0.40 & 0.45 & 0.50 & 0.55 & 0.60 & 0.65\end{array}$ $\begin{array}{llllllll}0.00 & 2.0076 & 1.9496 & 1.8989 & 1.8541 & 1.8139 & 1.7775 & 1.7444\end{array}$ $\begin{array}{lllllllll}0.05 & 1.7015 & 1.6609 & 1.6249 & 1.5927 & 1.5634 & 1.5367 & 1.5121\end{array}$ $\begin{array}{lllllllll}0.10 & 1.6055 & 1.5695 & 1.5375 & 1.5087 & 1.4825 & 1.4585 & 1.4363\end{array}$ $\begin{array}{lllllllll}0.15 & 1.5404 & 1.5073 & 1.4778 & 1.4512 & 1.4270 & 1.4047 & 1.3841\end{array}$ $\begin{array}{lllllllll}0.20 & 1.4903 & 1.4594 & 1.4317 & 1.4067 & 1.3839 & 1.3629 & 1.3435\end{array}$ $\begin{array}{lllllllll}0.25 & 1.4493 & 1.4201 & 1.3939 & 1.3702 & 1.3485 & 1.3286 & 1.3101\end{array}$ $\begin{array}{lllllllll}0.30 & 1.4146 & 1.3867 & 1.3617 & 1.3391 & 1.3183 & 1.2993 & 1.2816\end{array}$ $\begin{array}{lllllllll}0.35 & 1.3844 & 1.3577 & 1.3337 & 1.3119 & 1.2920 & 1.2736 & 1.2566\end{array}$ $\begin{array}{lllllllll}0.40 & 1.3577 & 1.3319 & 1.3088 & 1.2878 & 1.2686 & 1.2509 & 1.2344\end{array}$ $\begin{array}{lllllllll}0.45 & 1.3337 & 1.3088 & 1.2865 & 1.2662 & 1.2475 & 1.2304 & 1.2144\end{array}$ $\begin{array}{llllllll}0.50 & 1.3119 & 1.2878 & 1.2662 & 1.2465 & 1.2284 & 1.2117 & 1.1962\end{array}$ $\begin{array}{lllllllll}0.55 & 1.2920 & 1.2686 & 1.2475 & 1.2284 & 1.2108 & 1.1946 & 1.1795\end{array}$ $\begin{array}{lllllllll}0.60 & 1.2736 & 1.2509 & 1.2304 & 1.2117 & 1.1946 & 1.1787 & 1.1640\end{array}$ $\begin{array}{llllllll}0.65 & 1.2566 & 1.2344 & 1.2144 & 1.1962 & 1.1795 & 1.1640 & 1.1496\end{array}$ $\begin{array}{lllllllll}0.70 & 1.2407 & 1.2191 & 1.1995 & 1.1817 & 1.1654 & 1.1503 & 1.1362\end{array}$ $\begin{array}{llllllll}0.75 & 1.2259 & 1.2047 & 1.1856 & 1.1682 & 1.1522 & 1.1374 & 1.1236\end{array}$ $\begin{array}{lllllllll}0.80 & 1.2119 & 1.1912 & 1.1725 & 1.1554 & 1.1397 & 1.1252 & 1.1117\end{array}$ $\begin{array}{llllllll}0.85 & 1.1987 & 1.1784 & 1.1601 & 1.1433 & 1.1280 & 1.1137 & 1.1005\end{array}$ $\begin{array}{llllllll}0.90 & 1.1862 & 1.1663 & 1.1483 & 1.1319 & 1.1168 & 1.1028 & 1.0898\end{array}$ $\begin{array}{llllllll}0.95 & 1.1744 & 1.1548 & 1.1372 & 1.1211 & 1.1062 & 1.0925 & 1.0797\end{array}$ $\begin{array}{lllllllll}1.00 & 1.1631 & 1.1439 & 1.1266 & 1.1107 & 1.0961 & 1.0826 & 1.0701\end{array}$ 
Table 4a. (Continued)

\begin{tabular}{|c|c|c|c|c|c|c|c|}
\hline$(X, Y)$ & 0.70 & 0.75 & 0.80 & 0.85 & 0.90 & 0.95 & 1.00 \\
\hline .00 & 1.7139 & 1.6858 & 1.6596 & 1.6353 & 1.6124 & 1.5910 & 1.5708 \\
\hline .05 & 1.4894 & 1.4682 & 1.4484 & 1.4298 & 1.4124 & 1.3959 & 1.3802 \\
\hline .10 & 1.4158 & 1.3966 & 1.3787 & 1.3618 & 1.3459 & 1.3309 & 1.3166 \\
\hline .15 & 1.3650 & 1.3471 & 1.3304 & 1.3147 & 1.2998 & 1.2858 & 1.2724 \\
\hline .20 & 1.3255 & 1.3086 & 1.2928 & 1.2779 & 1.2638 & 1.2505 & 1.2378 \\
\hline .25 & 1.2929 & 1.2768 & 1.2617 & 1.2475 & 1.2341 & 1.2213 & 1.2092 \\
\hline .30 & 1.2651 & 1.2497 & 1.2352 & 1.2215 & 1.2086 & 1.1963 & 1.1847 \\
\hline .35 & 1.2407 & 1.2259 & 1.2119 & 1.1987 & 1.1862 & 1.1744 & 1.1631 \\
\hline .40 & 1.2191 & 1.2047 & 1.1912 & 1.1784 & 1.1663 & 1.1548 & 1.1439 \\
\hline .45 & 1.1995 & 1.1856 & 1.1725 & 1.1601 & 1.1483 & 1.1372 & 1.1266 \\
\hline .50 & 1.1817 & 1.1682 & 1.1554 & 1.1433 & 1.1319 & 1.1211 & 1.1107 \\
\hline .55 & 1.1654 & 1.1522 & 1.1397 & 1.1280 & 1.1168 & 1.1062 & 1.0961 \\
\hline .60 & 1.1503 & 1.1374 & 1.1252 & 1.1137 & 1028 & 1.0925 & 1.0826 \\
\hline .65 & 1.1362 & 1.1236 & 1.1117 & 1. & 1.0898 & 1.0797 & 1.0701 \\
\hline .70 & 1.1231 & 1.1107 & 1.0991 & 1.0881 & 1.0776 & 1.0677 & 1.0583 \\
\hline .75 & 1.1107 & 1.0986 & 1.0872 & 1.0764 & 0662 & 1.0565 & 1.0472 \\
\hline .80 & 1.0991 & 1.0872 & 1.0760 & 654 & 554 & 459 & 1.0367 \\
\hline 0.85 & 1.0881 & 1.0764 & 1.0654 & 1.0550 & 1.0452 & 1.0358 & 1.0269 \\
\hline 0.90 & 1.0776 & 1.0662 & 1.0554 & 1.0452 & 1.0355 & 1.0263 & 1.0175 \\
\hline .95 & 1.0677 & 1.0565 & 1.0459 & 1.0358 & 1.0263 & 1.0172 & 1.0085 \\
\hline 1.00 & 1.0583 & 1.0472 & 1.0367 & 1.0269 & 0175 & 1.0085 & 1.0000 \\
\hline
\end{tabular}


Table 4b. Numerical table of $R_{G}(x, y, 1)$

\begin{tabular}{|c|c|c|c|c|c|c|c|}
\hline$(X, Y)$ & 0.00 & 0.05 & 0.10 & 0.15 & 0.20 & 0.25 & 0.30 \\
\hline 0.00 & 0.5000 & 0.5302 & 0.5524 & 0.5717 & 0.5892 & 0.6055 & 0.6208 \\
\hline 0.05 & 0.5302 & 0.5559 & 0.5763 & 0.5945 & 0.6112 & 0.6267 & 0.6415 \\
\hline 0.10 & 0.5524 & 0.5763 & 0.5958 & 0.6133 & 0.6295 & 0.6446 & 0.6589 \\
\hline 0.15 & 0.5717 & 0.5945 & 0.6133 & 0.6303 & 0.6460 & 0.6608 & 0.6748 \\
\hline 0.20 & 0.5892 & 0.6112 & 0.6295 & 0.6460 & 0.6614 & 0.6759 & 0.6896 \\
\hline 0.25 & 0.6055 & 0.6267 & 0.6446 & 0.6608 & 0.6759 & 0.6901 & 0.7036 \\
\hline 0.30 & 0.6208 & 0.6415 & 0.6589 & 0.6748 & 0.6896 & 0.7036 & 0.7169 \\
\hline 0.35 & 0.6354 & 0.6555 & 0.6726 & 0.6882 & 0.7028 & 0.7166 & 0.7297 \\
\hline 0.40 & 0.6452 & 0.6689 & 0.6857 & 0.7011 & 0.7154 & 0.7290 & 0.7420 \\
\hline 0.45 & 0.6625 & 0.6818 & 0.6983 & 0.7135 & 0.7276 & 0.7410 & 0.7538 \\
\hline 0.50 & 0.6753 & 0.6942 & 0.7105 & 0.7254 & 0.7394 & 0.7527 & 0.7653 \\
\hline 0.55 & 0.6877 & 0.7063 & 0.7223 & 0.7371 & 0.7509 & 0.7640 & 0.7765 \\
\hline 0.60 & 0.6997 & 0.7180 & 0.7338 & 0.7484 & 0.7620 & 0.7750 & 0.7874 \\
\hline 0.65 & 0.7113 & 0.7294 & 0.7450 & 0.7594 & 0.7729 & 0.7857 & 0.7980 \\
\hline 0.70 & 0.7227 & 0.7404 & 0.7559 & 0.7701 & 0.7835 & 0.7962 & 0.8083 \\
\hline 0.75 & 0.7337 & 0.7513 & 0.7665 & 0.7806 & 0.7938 & 0.8064 & 0.8185 \\
\hline 0.80 & 0.7445 & 0.7618 & 0.7769 & 0.7908 & 0.8039 & 0.8164 & 0.8284 \\
\hline 0.85 & 0.7551 & 0.7721 & 0.7871 & 0.8009 & 0.8139 & 0.8262 & 0.8381 \\
\hline 0.90 & 0.7654 & 0.7823 & 0.7970 & 0.8107 & 0.8236 & 0.8359 & 0.8476 \\
\hline 0.95 & 0.7755 & 0.7922 & 0.8068 & 0.8204 & 0.8331 & 0.8453 & 0.8570 \\
\hline .00 & 0.7854 & 0.8019 & 0.8164 & 0.8299 & 0.8425 & 0.8546 & 0.8662 \\
\hline
\end{tabular}


Tab1e 4b. (Continued)

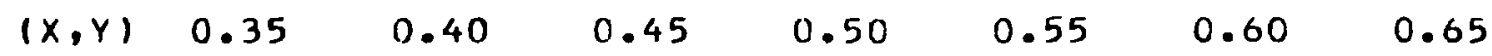

$\begin{array}{llllllll}0.00 & 0.6354 & 0.6492 & 0.6625 & 0.6753 & 0.6877 & 0.6997 & 0.7113\end{array}$

$\begin{array}{llllllll}0.05 & 0.6555 & 0.6689 & 0.6818 & 0.6942 & 0.7063 & 0.7180 & 0.7294\end{array}$

$\begin{array}{llllllll}0.10 & 0.6726 & 0.6857 & 0.6983 & 0.7105 & 0.7223 & 0.7338 & 0.7450\end{array}$

$\begin{array}{llllllll}0.15 & 0.6882 & 0.7011 & 0.7135 & 0.7254 & 0.7371 & 0.7484 & 0.7594\end{array}$

$\begin{array}{llllllll}0.20 & 0.7028 & 0.7154 & 0.7276 & 0.7394 & 0.7509 & 0.7620 & 0.7729\end{array}$

$\begin{array}{llllllll}0.25 & 0.7166 & 0.7290 & 0.7410 & 0.7527 & 0.7640 & 0.7750 & 0.7857\end{array}$

$\begin{array}{llllllll}0.30 & 0.7297 & 0.7420 & 0.7538 & 0.7653 & 0.7765 & 0.7874 & 0.7980\end{array}$

$\begin{array}{llllllll}0.35 & 0.7423 & 0.7544 & 0.7661 & 0.7775 & 0.7885 & 0.7993 & 0.8098\end{array}$

$\begin{array}{llllllll}0.40 & 0.7544 & 0.7664 & 0.7780 & 0.7892 & 0.8002 & 0.8108 & 0.8212\end{array}$

$\begin{array}{llllllll}0.45 & 0.7661 & 0.7780 & 0.7895 & 0.8006 & 0.8114 & 0.8220 & 0.8323\end{array}$

$\begin{array}{llllllll}0.50 & 0.7775 & 0.7892 & 0.8006 & 0.8116 & 0.8223 & 0.8328 & 0.8430\end{array}$

$\begin{array}{llllllll}0.55 & 0.7885 & 0.8002 & 0.8114 & 0.8223 & 0.8330 & 0.8433 & 0.8535\end{array}$

$\begin{array}{llllllll}0.60 & 0.7993 & 0.8108 & 0.8220 & 0.8328 & 0.8433 & 0.8536 & 0.8637\end{array}$

$\begin{array}{llllllll}0.65 & 0.8098 & 0.8212 & 0.8323 & 0.8430 & 0.8535 & 0.8637 & 0.8736\end{array}$

$\begin{array}{lllllllll}0.70 & 0.8200 & 0.8314 & 0.8423 & 0.8530 & 0.8634 & 0.8735 & 0.8834\end{array}$

$\begin{array}{llllllll}0.75 & 0.8301 & 0.8413 & 0.8522 & 0.8628 & 0.8731 & 0.8831 & 0.8929\end{array}$

$\begin{array}{llllllll}0.80 & 0.8399 & 0.8510 & 0.8618 & 0.8723 & 0.8826 & 0.8925 & 0.9023\end{array}$

$\begin{array}{llllllll}0.85 & 0.8495 & 0.8606 & 0.8713 & 0.8817 & 0.8919 & 0.9018 & 0.9115\end{array}$

$\begin{array}{lllllllll}0.90 & 0.8590 & 0.8699 & 0.8806 & 0.8909 & 0.9010 & 0.9109 & 0.9205\end{array}$

$\begin{array}{llllllll}0.95 & 0.8682 & 0.8791 & 0.8897 & 0.9000 & 0.9100 & 0.9198 & 0.9294\end{array}$

$\begin{array}{llllllll}1.00 & 0.8774 & 0.8882 & 0.8987 & 0.9089 & 0.9189 & 0.9286 & 0.9381\end{array}$ 
Table 4b. (Continued)

\begin{tabular}{|c|c|c|c|c|c|c|c|}
\hline$(X, Y)$ & 0.70 & 0.75 & 0.80 & 0.85 & 0.90 & 0.95 & 1.00 \\
\hline 0.00 & 0.7227 & 0.7337 & 0.7445 & 0.7551 & 0.7654 & 0.7755 & 0.7854 \\
\hline 0.05 & 0.7404 & 0.7513 & 0.7618 & 0.7721 & 0.7823 & 0.7922 & 0.8019 \\
\hline 0.10 & 0.7559 & 0.7665 & 0.7769 & 0.7871 & 0.7970 & 0.8068 & 0.8164 \\
\hline 0.15 & 0.7701 & 0.7806 & 0.7908 & 0.8009 & 0.8107 & 0.8204 & 0.8299 \\
\hline 0.20 & 0.7835 & 0.7938 & 0.8039 & 0.8139 & 0.8236 & 0.8331 & 0.8425 \\
\hline 0.25 & 0.7962 & 0.8064 & 0.8164 & 0.8262 & 0.8359 & 0.8453 & 0.8546 \\
\hline 0.30 & 0.8083 & 0.8185 & 0.8284 & 0.8381 & 0.8476 & C. 8570 & 0.8662 \\
\hline 0.35 & 0.8200 & 0.8301 & 0.8399 & 0.8495 & 0.8590 & 0.8682 & 0.8774 \\
\hline 0.40 & 0.8314 & 0.8413 & 0.8510 & 0.8606 & 0.8699 & 0.8791 & 0.8882 \\
\hline 0.45 & 0.8423 & 0.8522 & 0.8618 & 0.8713 & 0.8806 & 0.8897 & 0.8987 \\
\hline 0.50 & 0.8530 & 0.8628 & 0.8723 & 0.8817 & 0.8909 & 0.9000 & 0.9089 \\
\hline 0.55 & 0.8634 & 0.8731 & 0.8826 & 0.8919 & 0.9010 & 0.9100 & 0.9189 \\
\hline 0.60 & C. 8735 & 0.8831 & 0.8925 & 0.9018 & 0.9109 & 0.9198 & 0.9286 \\
\hline 0.65 & 0.8834 & 0.8929 & 0.9023 & 0.9115 & 0.9205 & 0.9294 & 0.9381 \\
\hline 0.70 & 0.8931 & 0.9026 & 0.9119 & 0.9210 & 0.9300 & 0.9388 & 0.9475 \\
\hline 0.75 & 0.9026 & 0.9120 & 0.9212 & 0.9303 & 0.9392 & 0.9480 & 0.9566 \\
\hline 0.80 & 0.9119 & 0.9212 & 0.9304 & 0.9394 & 0.9483 & 0.9570 & 0.9656 \\
\hline 0.85 & 0.9210 & 0.9303 & 0.9394 & 0.9484 & 0.9572 & 0.9659 & 0.9744 \\
\hline 0.90 & 0.9300 & 0.9392 & 0.9483 & 0.9572 & 0.9660 & 0.9746 & 0.9831 \\
\hline 0.95 & 0.9388 & 0.9480 & 0.9570 & 0.9659 & 0.9746 & 0.9832 & 0.9916 \\
\hline 1.00 & 0.9475 & 0.9566 & 0.9656 & 0.9744 & 0.9831 & 0.9916 & 1.0000 \\
\hline
\end{tabular}




\section{LITERATURE CITED}

1. Carlson, B. C. Lauricella's hypergeonetric function $F_{D}$. Journal of Mathematical Analysis and Applications 7:452-470. 1963.

2. Carlson, B. C. Normal elliptic integrals of the first and second kinds. Duke Mathematica l Journa 1 31: 405-419. 1964.

3. Byrd, P. F. and Friedman, M. D. Handbook of elliptic integrals for engineers and physicists. Berlin, Germany, Springer-Verlag. 1954.

4. Milne-Thoms on, L. M. Elliptic integrals. In Abramowitz, Milton and Stegun, Irene, eds. Handbook of mathematical functions. PP. 587-626. Washington, D. C., U. S. Government Printing Office. 1964.

5. Crobner, Wolfgang and Hofreiter, Nikolaus. Integraltafel. Parts 1 and 2. Vienna, Austria, Springer-Verlag. 1957 and 1958.

6. Carlson, B. C. On computing elliptic integrals and functions. To be published in Journal of Mathematics and Physics. circa July, 1965 . 


\section{ACKNOWLEDGEMENTS}

The author wishes to express his sincere gratitude to Dr. B. C. Carlson for both his professional and personal advice and encouragement. The author also wishes to thank two members of the Ames Laboratory Computer Service Group, Mr. James Delany and Mr. Frank Carlsen. Mr. Delany wrote the Fortran subroutine program to calculate $R_{F}$ and $R_{G}$ using quadratic transformations. Mr. Carlsen provided valuable advice for the computation of $R_{F}$ and $R_{G}$ directly from their power series expansions. 
X. APPENDIX: FORTRAN SUBROUTINE PROGRAM FOR

COMPUTING $R_{F}$ AND $R_{G}$ BY MEANS OF DESCENDING

GAUSS OR ASCENDING LANDEN TRANSFORMATIONS

This program has been written under the assumption that

$0 \leq x \leq y \leq z$. Particular values worthy of note are $R_{F}(0,0,1)=$ $\infty$ and $R_{G}(0,0,1)=1 / 2$.

SUBROUTINE ELINT (X,Y,Z,RF, RG,INF)

DIMENSION $V(3), W(3)$

$5 \quad \operatorname{IF}(X) \quad 7,8,8$

$8 \quad \mathrm{SQRTZ}=\mathrm{SQRTF}(\mathrm{Z})$

$\operatorname{IF}(\mathrm{Y}) 7,10,11$

$10 \quad \mathrm{INF}=1$

$\mathrm{RG}=.5 * \mathrm{SQRTZ}$

GOTO 7

$11 \quad$ INF $=0$

$9 \operatorname{IF}(\mathrm{Z}-\mathrm{X}) \quad 13,12,13$

$12 \mathrm{RF}=1 . / \mathrm{SQRTZ}$

$\mathrm{RG}=\mathrm{SQRTZ}$

GOTO 7

$13 \quad \mathrm{D}=\mathrm{Y}+\mathrm{Y}-\mathrm{X}-\mathrm{Z}$

$A=\operatorname{SQRTF}(Z-X)$

IF (D) $15,14,14$

$14 \quad \mathrm{~T}=\mathrm{SQRTZ}$

$\mathrm{H}=\mathrm{SQRTF}(\mathrm{X})$

$\mathrm{CS}=\mathrm{Z}-\mathrm{Y}$

GOTO 21

$15 \mathrm{~T}=\operatorname{SQRTF}(\mathrm{X})$

$\mathrm{H}=\mathrm{SQRTZ}$

$\mathrm{CS}=\mathrm{Y}-\mathrm{X}$

$21 \mathrm{~T}=.5 \%(\mathrm{~T}+\operatorname{SQRTF}(\mathrm{Y}))$

$\mathrm{N}=0$

$80 \quad A=.5 *(A+S Q R T F(A * A-C S))$

$\mathrm{CC}=(.25 * \mathrm{CS}) / \mathrm{A}$

$\mathrm{CS}=\mathrm{CC} * \mathrm{CC}$

$\mathrm{N}=\mathrm{N}+\mathrm{l}$

$\mathrm{V}(\mathrm{N})=\mathrm{A} * \mathrm{~A}-\mathrm{CS}$

$\mathrm{W}(\mathrm{N})=\mathrm{H}$

IF $(\mathrm{N}-1) \quad 81,82,81$ 


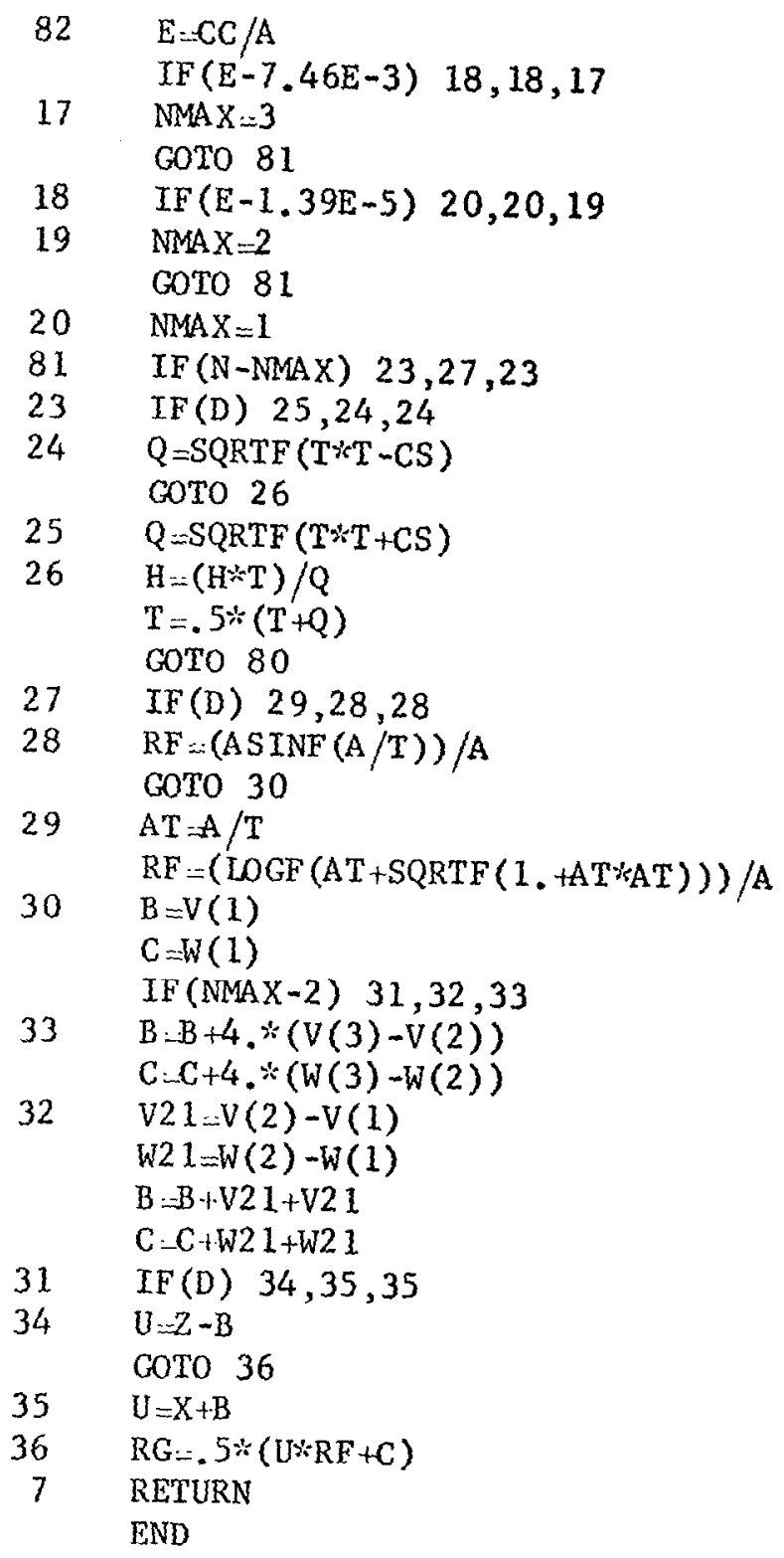


"The aeronautical and space activities of the United States shall be conducted so as to conlribute . . . to the expansion of buman knowledge of phenomena in the atmosphere and space. The Administiation shall provide for the widest practicable and appropriate dissemination of information concerning its activities and the results thereof."

-National Aeronautics and Space Act of 1958

\section{NASA SCIENTIFIC AND TECHNICAL PUBLICATIONS}

TECHNICAL REPORTS: Scientific and technical information considered important, complete, and a lasting contribution to existing knowledge.

TECHNICAL NOTES: Information less broad in scope but nevertheless of importance as a contribution to existing knowledge.

TECHNICAL MEMORANDUMS: Information receiving limited distribution because of preliminary data, security classification, or other reasons.

CONTRACTOR REPORTS: Technical information generated in connection with a NASA contract or grant and released under NASA auspices.

TECHNICAL TRANSLATIONS: Information published in a foreign language considered to merit NASA distribution in English.

TECHNICAL REPRINTS: Information derived from NASA activities and initially published in the form of journal articles.

SPECIAL PUBLICATIONS: Information derived from or of value to NASA activities but not necessarily reporting the results of individual NASA-programmed scientific efforts. Publications include conference proceedings, monographs, data compilations, handbooks, sourcebooks, and special bibliographies.

Details on the availability of these publications may be obtained from:

SCIENTIFIC AND TECHNICAL INFORMATION DIVISION

NATIONAL AERONAUTICS AND SPACE ADMINISTRATION

Washington, D.C. 20546 